\title{
Mutational analysis of $p 53$ gene in cervical cancer and useful polymorphic variants in exons 3 and 4
}

\author{
Michael A. Gbadegesin ${ }^{1 *}$ (D), Olabode E. Omotoso ${ }^{1}$, Timothy A. O. Oluwasola ${ }^{2}$, Clement A. Okolo ${ }^{3}$, \\ Opeyemi Soremekun', Gabriel O. Ogun', Abideen O. Oluwasola ${ }^{3}$ and Oyeronke A. Odunola
}

\begin{abstract}
Background: Factors contributing to the pathogenesis and progression of cervical cancer include poor attitude to screening and health intervention, late presentation, among others. Mutations in p53 gene have been attributed to several cancer cases. The present study was designed to find relationships between the mutation patterns in p53 gene and cervical carcinoma staging. Such knowledge could contribute to early diagnosis of cervical cancer.

Results: From the sequence analysis of p53 gene fragment isolated by polymerase chain reactions (PCR), nineteen (19) polymorphic variants were identified. Missense mutations occurred in $47 \%$ of the samples, $32 \%$ were silent mutations, $16 \%$ were frameshift mutations and $5 \%$ nonsense mutations. Socio-biological characteristics of the study participants revealed that $60 \%$ have husbands with multiple sexual partners and that only $23.3 \%$ of the participants have ever had the Papanicolaou (Pap) smear test prior to diagnosis, whilst 20\% were unaware of the screening test.

Conclusions: Increased severity of cervical carcinoma staging as revealed from the histopathological analysis was found to be associated with accumulation of higher levels of mutations in the p53 gene. Molecular analysis of p53 gene mutations may prove useful as a screening biomarker for cervical cancer.
\end{abstract}

Keywords: Genomic DNA, Cervical carcinoma, Gene mutation, Polymorphic variation

\section{Background}

Cancer is a multi-factorial disease that remains a serious global concern. Cervical carcinoma is the fourth most frequent cancer in women with a global incidence rate of 570,000 reported in 2018 , and representing $6.6 \%$ of all cancers in females [1]. Approximately $90 \%$ of cancerrelated deaths occur in low- and middle-income countries [2], with about $85 \%$ of the 250,000 deaths recorded annually from cervical cancer are reported in developing countries where most cases are presented in the late stages of the disease. The incidence of cervical cancer in Nigeria is about 250/100,000 with about 8000 deaths annually [3].

\footnotetext{
* Correspondence: magbadegesin@yahoo.com

${ }^{1}$ Cancer Research and Molecular Biology Laboratories, Department of Biochemistry, University of Ibadan, Ibadan, Nigeria

Full list of author information is available at the end of the article
}

Three major factors have been identified in cervical cancer pathogenesis out of which two are related to human papillomavirus (HPV) infection. These include the consequences of HPV DNA integration in the host genome, the effects of viral oncoproteins and the accumulation of cellular genetic damage not associated with HPV infection [4]. High risk of HPV infection, late diagnosis due to poor screening uptake and prognosis and low uptake of HPV vaccination have been attributed as the major factors culpable in the cervical cancer burden in women [4].

HPV is the primary causative biological agent involved in cervical cancer pathogenesis $[4,5]$. The high-risk HPV's DNA encodes the oncoproteins E6 and E7 which bind to p53 and retinoblastoma proteins, respectively. The binding of the E6 protein, through its interaction with the E6-associated protein (E6AP), to p53 induces 
the degradation of $\mathrm{p} 53$, the tumour suppressor protein [6] (as schematically shown in Fig. 1). This proteasomal degradation pathway could play a crucial role in cervical carcinogenesis through the promotion of cell cycle entry that leads to unregulated proliferation of invasive cells $[7,8]$.

On the other hand, the protooncogenes and tumour suppressor genes play vital roles in carcinogenesis [9]. The p53 protein (commonly referred to as the guardian of the genome), which contains 11 exons, is a nuclear phosphoprotein whose gene is located on the short arm of chromosome 17 at the $17 \mathrm{p} 13.1$ locus [10-12]. It plays an important role in the regulation of cell proliferation, the cell cycle, as well as apoptosis and senescence in response to DNA damage [13, 14], and is frequently mutated in most human cancers [15]. Most mutations observed in the $p 53$ gene are single base-pair substitutions and occur predominantly between codons 130 and 290 [5]. The $p 53$ gene has been rarely observed to be mutated in early cervical tumours [6]. In addition, some p53 mutant proteins are unsusceptible to E6-mediated degradation, thereby suggesting that $\mathrm{p} 53$ polymorphisms might be culpable in the variation of cell responses to the HPV infection [6].

Mutations in $p 53$ are also associated with genomic instability [16] and delay in cell cycle progression $[17,18]$. The proline-rich region of the $\mathrm{p} 53$ protein is essential for induction of apoptotic response to cellular stressors [19] and inhibition of tumourigenesis [20]. However, the E6 oncoprotein causes more efficient degradation of the arginine polymorph at codon 72 than the proline polymorph, thereby, reducing cellular levels of p53 protein and increasing the risk of HPV-associated cervical cancers in individuals with the arginine polymorph [21]. The first $p 53$ gene mutation in human cancer was described by Bakers and his team [22]. Codon 72 is located within the proline-rich region of the gene and may have a significant effect on the putative (sarcoma homology) SH3-binding domain [14]. Studies have linked genetic polymorphism of the codon 72 of $p 53$ to cervical cancer progression [8], and the variation in this codon can either be arginine (GCG) or proline (GGG).

The divergence in the polymorphic variations that exist in $p 53$ with respect to the pathogenesis of cervical cancer has been attributed to varying geographic locations, and the different environmental exposures [23]. It has also been reported that greater than $85 \%$ of known cancer-related $p 53$ mutations are missense mutations $[2,4]$. Some of the missense mutations resulting from single nucleotide substitutions can affect p53 conformation and result in inactive protein.

The exon 4 in the p53 gene is one of the largest, spanning 311 nucleotide base pairs (bp). It contains the proline-rich region and is essential for DNA specific binding, apoptosis, and transcription $[10,16]$.

To understand further the role of this tumoursuppressor gene mutation-pattern in cervical cancer, we performed a mutational analysis for the polymorphicvariations in the exons 3 and 4 of p53 gene in patients diagnosed with cervical cancer in Ibadan, Nigeria.

\section{Methods}

Study site, ethical review and samples collection

The University College Hospital (UCH)-University of Ibadan Institution Ethics Committee approved the study. Written informed consents wereobtained from all study participants before samples were taken. Cervical carcinoma tissues were obtained from such patients who presented at the day-casetheatre of the Obstetrics and Gynaecology Department for examination under anaesthesia, staging and cervical tissue biopsy as required for definitiveapproach to management. The tissue biopsies for the genomic DNA isolation were preserved in a DNA/RNA shieldTM, while about $5 \mathrm{~g}$ of the sampleswere preserved for histological studies at the Pathology Department of UCH. Molecular biology procedures were carried out at the Professor AbideenOluwasola Special Diagnostics Centre, UCH, Ibadan.

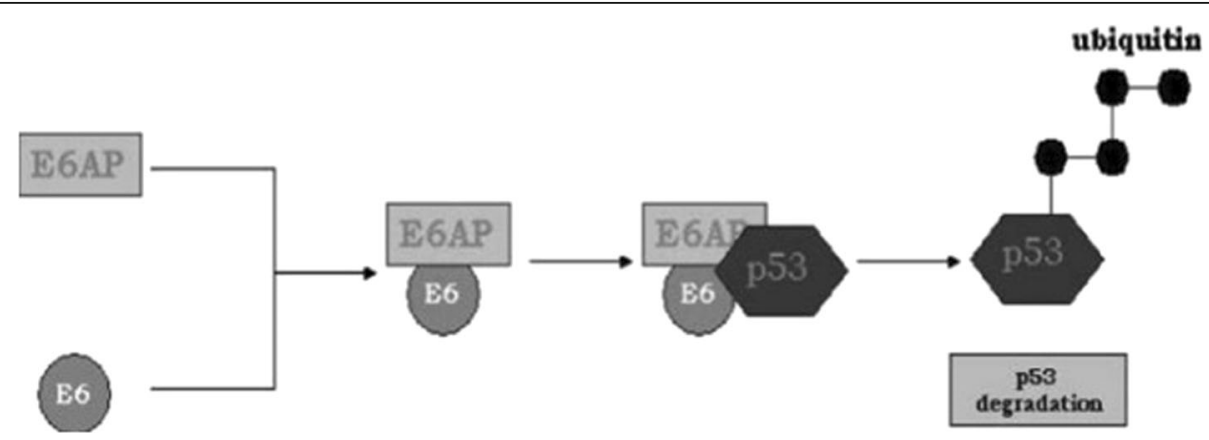

Fig. 1 The HPV E6 oncoprotein induces p53 proteasomal degradation via the ubiquitin degradation pathway. The E6 oncoprotein binds with the ubiquitin-protein ligase E6-associated protein (E6AP). The E6AP-E6 complex associates with p53, E6AP then catalyses multi-ubiquitination of p53 leading to the degradation of p53 [7] 


\section{Histological analysis}

Cervical tissue biopsy samples (5 g per sample) obtained from the study subjects were sent to the Pathology Department, College of Medicine for analysis for tumours. This involves histological staining, sectioning and examination under a microscope.

\section{DNA isolation}

High molecular weight genomic DNA samples were purified from the cervical tissues using Quick-DNA ${ }^{\mathrm{TM}}$ Miniprep Plus Kit as specified in the kit's manual. The purified DNA was quantified on a NanoDrop ${ }^{\text {TM }} 2000$ spectrophotometer.

\section{PCR amplification of $p 53$ gene fragment}

The $p 53$ gene fragment was amplified from the genomic DNA using forward (5' TGAAGTCTCATGGAAGCC AGC 3') and reverse (5' GCTCTTTTTCACCCATCT ACAG 3') primers at the optimum PCR conditions in a total reaction volume of $25 \mu$ l. Purified genomic DNA from an established cancer-free individual was used as the control. The amplification reactions were carried out in a programmable thermal cycler using the following sequence: Initial denaturation at $95^{\circ} \mathrm{C}$ for $5 \mathrm{~min}$, followed by 35 cycles of denaturation at $94^{\circ} \mathrm{C}$ for $45 \mathrm{~s}$, annealing at $55^{\circ} \mathrm{C}$ for $60 \mathrm{~s}$, and extension at $72^{\circ} \mathrm{C}$ for $60 \mathrm{~s}$, and a final extension step at $72^{\circ} \mathrm{C}$ for $7 \mathrm{~min}$, making a total run of about $1 \mathrm{~h}, 56 \mathrm{~min}$ at $9600 \mathrm{ramp}$ to ensure a complete extension of all amplicons.

\section{Analysis of the PCR products}

Four (4)-microliter aliquots of the PCR products were applied to $1.5 \%$ agarose gel to check that the right size product is obtained. Electrophoresis was performed in TAE (tris-acetate-ethyl diamine tetra acetate) buffer at a voltage of 100 volts, a current of 400 Amps for $45 \mathrm{~min}$. The ethidium-bromide stained gel was viewed on a VIVI LBER transilluminator. The two strands of DNA were then sequenced from the representative samples.

\section{DNA sequencing and sequence analysis}

Based on the findings from the histological analyses, amplified DNA from representative samples for normal cervical epithelium, well-differentiated cervical cell, moderately differentiated malignant cells and poorly differentiated malignant epithelial neoplasm were sequenced. The chromatograms were viewed and edited using the combination of FinchTv version 1.4.0 and SnapGene Viewer version 4.2.9 for specificity and accuracy. The nucleotide sequences were then exported from the chromatogram and identified by submitting to the NCBI BLAST-N (National Centre for Biotechnology Information Basic Local Alignment Search Tool for nucleotide) page. Reference nucleotide sequences were also mined from the same web site. Furthermore, TCOFFEE was used for the multiple sequence alignment of the sequences. EXPASY was used to translate the DNA nucleotide sequence to the protein amino acids sequence. Catalogue of Somatic Mutations in Cancer (COSMIC), International Agency for Research in Cancer (IARC) and NCBI databases were used for the analysis of the gene mutations. Nucleotide sequences from the present study have been submitted to the NCBI public database under the accession numbers MN982161 to MN982165.

\section{Results}

The socio-biological characteristics of the participants are as presented in Table 1.

Using genomic DNA isolated from the cervical tissues of the study participants, highly specific amplification of exons 3 and 4, which spans the coding region of the gene that encompasses the proline-rich region, activation domain, and the sequence specific DNA binding domain were successful. The PCR products analysis on agarose gel revealed that the correct sized ( $350 \mathrm{bps})$ gene fragments were amplified in most positive reactions (Fig. 2).

Thirty selected cases (representing the differentiation stages) of human cervical cancer DNA sequences were analysed for polymorphic variations in the proline-rich

Table 1 The socio-biological characteristics of the participants $(N=30)$

\begin{tabular}{lcl}
\hline & Frequency & Percentage (\%) \\
\hline Age range (in years) & 7 & \\
$36-45$ & 3 & 23.3 \\
$46-55$ & 8 & 10.0 \\
$56-65$ years & 3 & 26.7 \\
$66-75$ years & 6 & 10.0 \\
$76-85$ years & 3 & 20.0 \\
$86-95$ years & & 10.0 \\
Marital status & 15 & \\
Married & 1 & 50.0 \\
Divorced & 14 & 3.3 \\
Widowed & 46.7 \\
Pap smear test awareness/uptake & \\
Never aware & 6 & 20.0 \\
Ever done & 7 & 23.3 \\
Aware but never done & 17 & 56.7 \\
Husband's known number of sexual partners & \\
1 & 12 & 40.0 \\
2 & 13 & 43.3 \\
Greater than 2 & 5 & 16.7 \\
\hline
\end{tabular}




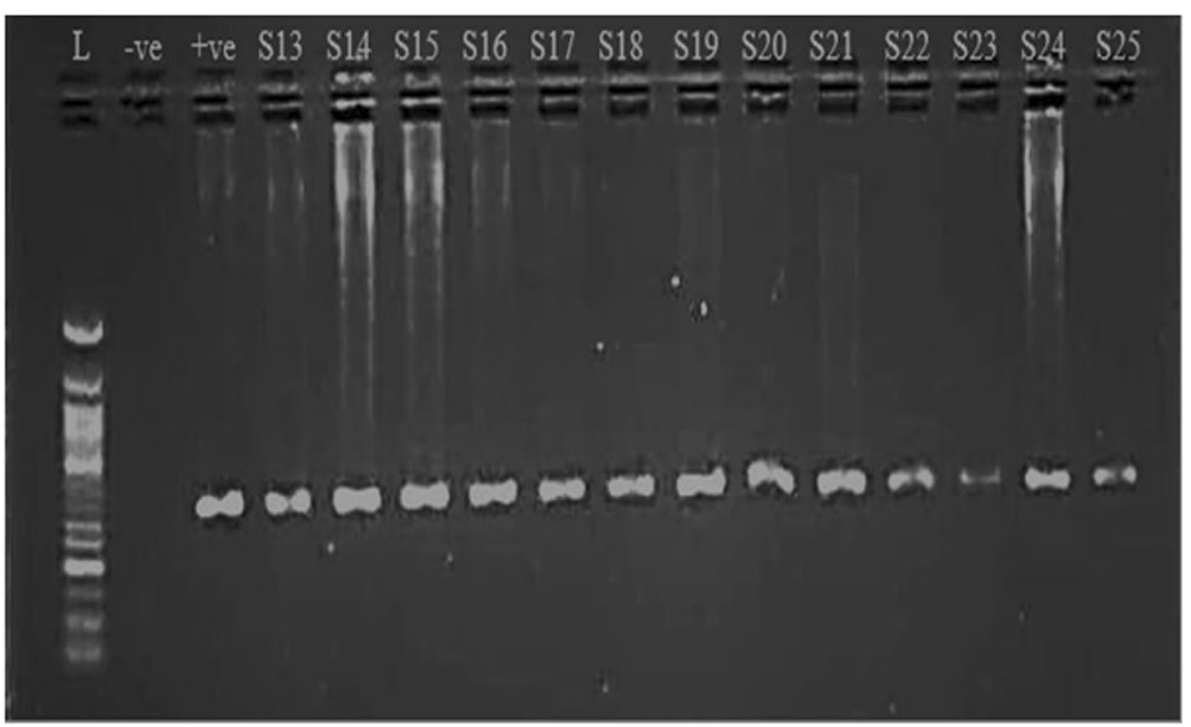

Fig. 2 Representative ethidium bromide-stained agarose gel of the PCR products (350 bps) amplified from genomic DNA isolated from the cervical tissues using primers as specified in the "Methods" section. The first lane $(\mathrm{L})$ represents the marker (50 base pair DNA ladder), lane (-ve) is the negative control (no DNA template), lane (+ve) is another control (template is genomic DNA from individual pre-tested to be cervical cancer free) and lanes S13-S25 are PCR products using genomic DNA templates from respective biopsy samples

region, activation domain and the sequence specific DNA binding domain of the $p 53$ gene. Result of the multiple sequence alignment of the sample sequences and the reference sequence (accession number: $\mathrm{NG}_{-}$ 017013) [24] is shown in Fig. 3.

The photomicrographs from the histology studies of different staging of the cervical cancer are presented in Fig. 3. The photomicrograph in Fig. 3a shows normal cervical epithelium, with the epithelial wall of the cervix still intact and normal proliferation of cells within the cervix, whilst the one in Fig. 3b shows well-differentiated cervical cells. These cells show extensive areas of necrosis and haemorrhage alongside areas revealing keratin pearls formation by the tumour cells and underlying infiltration of the stroma. Figure $4 \mathrm{c}$ shows moderately differentiated malignant cells with focal areas of necrosis as well as stroma infiltration by eosinophils, lymphocytes and plasma cells, and invasion of the fibro-collagenous stroma. Poorly differentiated, malignant epithelial neoplasm is shown in Fig. 3d with mass encroachment of proliferating cells beyond the epithelial wall of the cervix. It was observed that the samples accumulated more mutations with increased severity of differentiation.

\section{Nucleotide variations and polymorphisms from the DNA mutation analysis}

The observed distribution of nucleotide substitutions and polymorphic variations in the samples were in the following orders: Missense mutations occurred in $47 \%$ of the samples, $32 \%$ were silent mutations, $16 \%$ were frameshift mutation and 5\% nonsense mutation was observed in the cervical tissue samples. The specific codons involved are listed below, using the standard one-letter code for amino acids (W-Tryptophan; LLeucine; K-Lysine; N-Asparagine; I-Isoleucine; $\mathrm{M}$-Methionine; $\mathrm{R}$-Arginine; $\mathrm{P}$-Proline; A-Alanine; V-Valine; Q-Glutamine; E-Glutamate). In addition, fs* stands for frameshift.

\section{Missense mutations}

- At codon $30(\mathrm{~N} 30 \mathrm{~K})$, there was a substitution of Lysine (K) for Asparagine (N)

- At codon 35 (L35W), there was a substitution of Tryptophan (W) for Leucine (L)

- At codon 66 (M66I), Isoleucine (I) substituted for Methionine (M)

- At codon 72 (P72R) and 82 (P82R), Arginine (R) substituted for Proline (P)

- At codon 73 (V73A), Alanine (A) substituted for Valine (V)

- At codon 77 (P77A/Q), Alanine (A) and Glutamine (Q) substituted for Proline (P)

- At codon 86 (A86E), Glutamate (E) substituted for Alanine (A)

\section{Silent mutations}

- codon 74 (A74A)

- codon 79 (A79A)

- codon 81 (T81T)

- codon 83 (A83A) and 84 (A84A)

- codon 85 (P85P) 


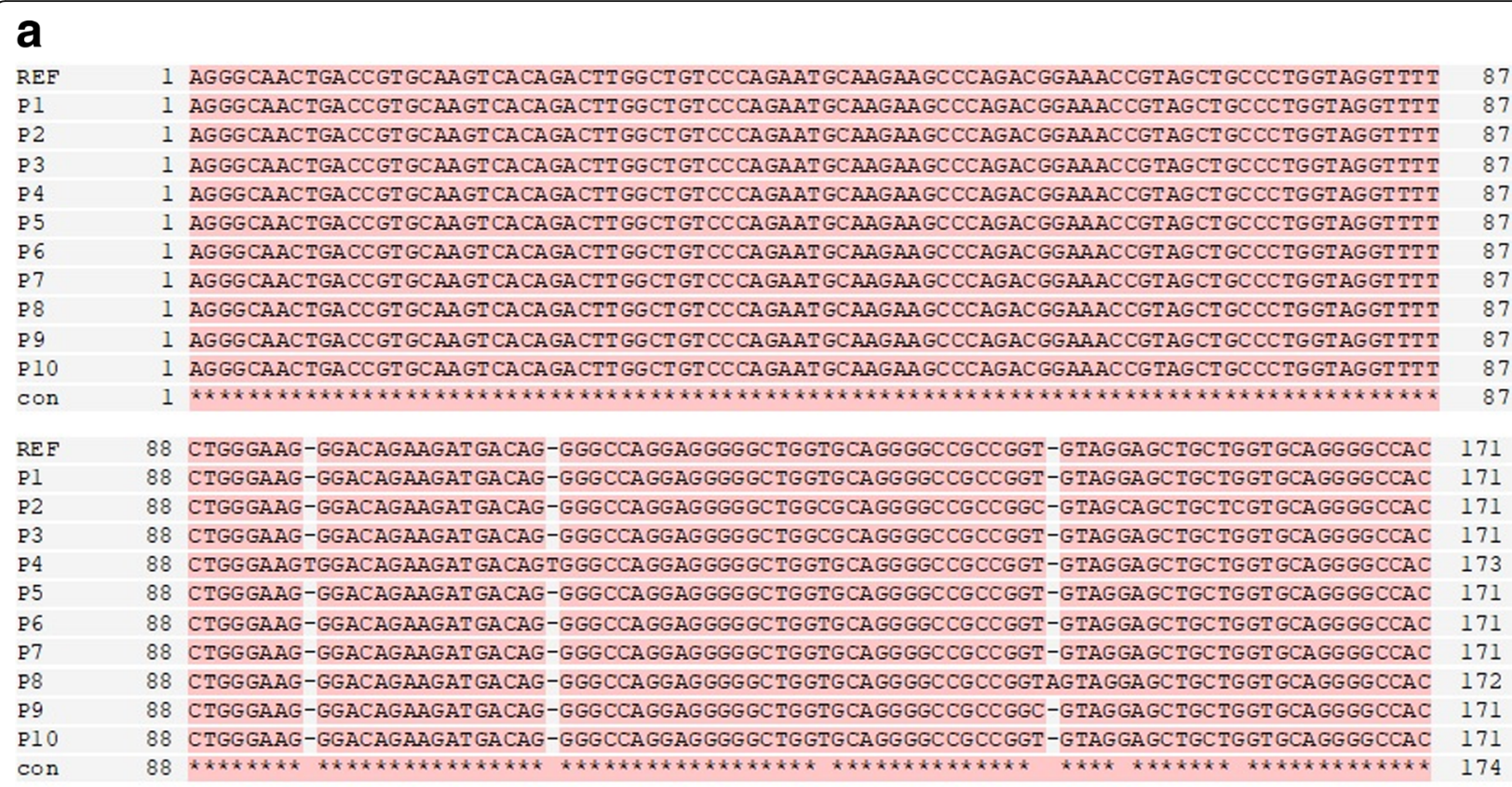

\section{b}

REF 172 GGGGGGAGCAGCCTCTGGCATTCTGGGAGCT TCATCTGGACCTGGGTCTTCAGTGAACCATTGTTCAATATCGTCCGGGGACAGCAT

P1 172 GCGGGGAGCAGCCTCTGGCATTCTGGGAGCT TCATCTGGACCTGGGTCTTCAGTGAACCATTGTTCAATATCGTCCGGGGACAGCAT

P2 172 GGGGGGAGCAGCCTCTGGCATTCTGGGAGCT TCATCTGGACCTGGGTCTTCAGTGAACCATTGTTCAATATCGTCCGGG GACAGCAT

172 GGGGGGAGCAGCCTCTGG-ATTCTGGGAGCT TCATCTGGACCT GGGTCTTCAGTGAACCATTGTTCAATATCGTCCGGGGACAGCAT

174 GGGGGGAGCAGCCTCTGGCATTCTGGGAGCT TCATCTGGACCT GGGTCTTCAGTGAACCATTGTTCAATATCGTCCGGGGACAGCAT

172 GGGGGGAGCAGCCTCTGG-ATTCTGGGAGCT TCATCTGGACCT GGGTCTTCAGTGAACCATTGTTCAATATCGTCCGGGGACAGCAT

172 GCGGGGA GCAGCCTCTGGCATTCTGGGAGCT TCATCTGGACCT GGGTCTTCAGTGAACCATTGTTCAATATCGTCCGGGGACAGCAT

172 GGGGGGAGCAGCCTCTGGCATTCTGGGAGCT TCATCTGGACCT GGGTCTTCAGTGAACCATTGTTCAATATCGTCCGGGGACAGCAT

173 GCGGGGAGCAGCCTCTGGCATTCTGGGAGCT TCATCTGGACCT GGGTCTTCAGTGAACCATTGTTCAATATCGTCCGGGGACAGCAT

172 GCGGGGAGCAGCCTCTGGCATTCTGGGAGCT TCATCTGGACCT GGGTCTTCAGTGAACCATTGTTCAATATCGTCCGGGGACAGCAT

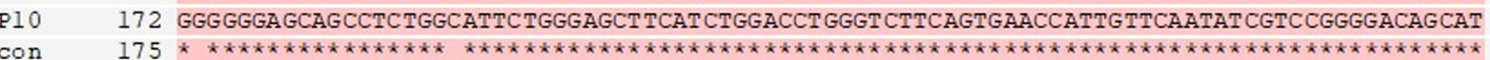

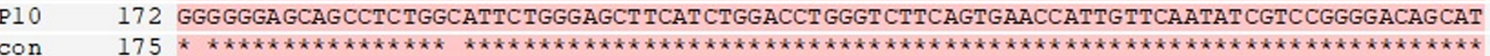

REF 259 CAAATCATCCATTGCTIGGGACGGCAAGGGGGCTGTAGATGGGTGAA-AAGAGC-A 313

P1 259 CAAATCATCCATTGCTTGGGACGGCAAGGGGGATGTAGATGGGTGAAAAAGAGC-A 314

P2 259 CAAATCATCCATTGCTTGGGACGGCAAGGGGGACTGTAGATCGGTGAAAAAGAGCCA 315

P3 257 CAAATCATCCATTGCTTGGGACGGCAAGGGGGACTGTAGATGGGTGAAAAGAGC-A 312

P4 261 CAAATCATCCATTGCTTGGGACGGCAAGGGGGACTGTAGATGGGTGAAAAAGAGC-A 316

P5 258 CAAATCATCCATTGCTTGGGACGGCAAGGGGGACTGTAGATGGGTGAAAAAGAGC-A 313

P6 259 CAAATCATCCATTGCTTGGGACGGCAAGGGGGACTGTAGATGGGTGAAAAAGAGC-A 314

P7 259 CAAATCATCCATTGCTTGGGACGGCAAGGGGGACTGTAGATGGGTGAAAAAGAGC-A 314

P8 260 CAAATCATCCATTGCTTGG GACGGCAAGGGGGACTGTAGATGGGTGAAAAAGAGC-A 315

P9 259 CAAATCATCCATTGCTTGGGACGGCAAGGGGGACTGTAGATGGGTGAAAAAGAGC-A 314

P10 259 CAAATCATCCATTGCTTGGGACGGCAAGGGGGACTGTAGATGGGTGAAAAAGAGC-A 314

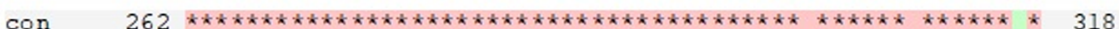

Fig. 3 Multiple sequence alignment (using T-COFFEE MSA tool) of the nucleotide sequences (P1-P10) showing the nucleotide sequence with respect to the reference sequence (accession number: NG_017013). The con shows the conservation pattern of the sequences; an asterisk illustrates a conserved nucleotide across the sequences whilst an empty con shows a variation (SNV or SNP) in the sequences

\section{Frameshift (insertion and deletion)}

- At codon 26 (L26fs*), 66 (M66fs*) and 119 (A119fs*)

\section{Nonsense mutation}

- A stop codon was introduced at codon 103 (Y103X) instead of Tyrosine (Y)

\section{Discussion}

Cervical cancer is not spontaneous but occurs through a multistep process [22] and develops with age [25, 26]. The relationship between age and cervical cancer development is evident in the present study. The mean age of study participants is $59 \pm 16.9$ years; the age category 

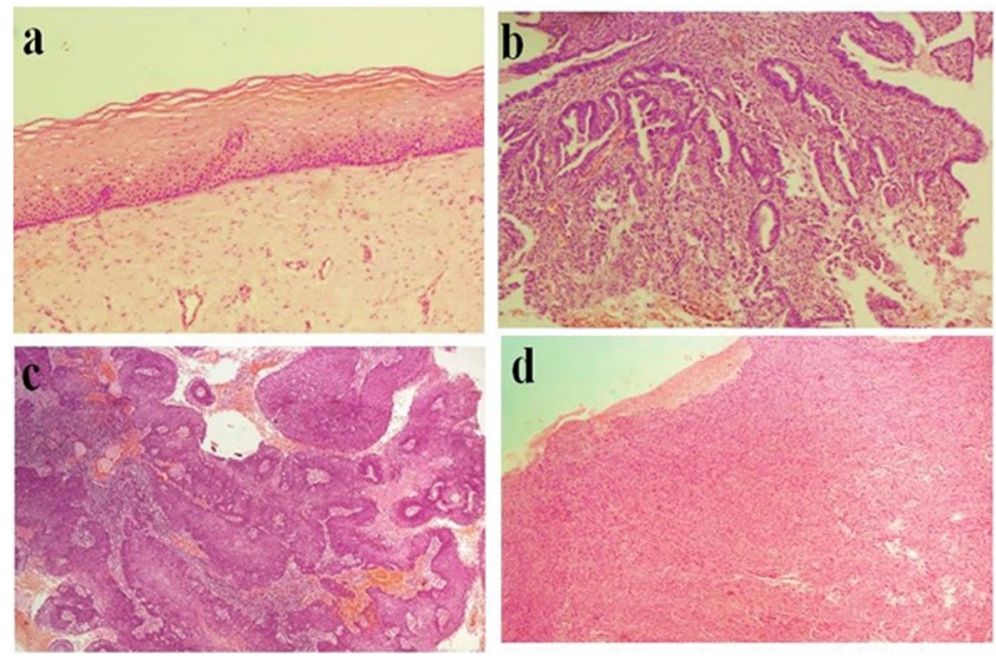

Fig. 4 Photomicrograph of biopsies from Pathology Department; P10 (a), P7 (b), P3 (c) and P2 (d) are representives of normal cervical epithelium and cervicitis (26.7\%), well-differentiated/polyp (30\%), moderately differentiated (30\%) and poorly differentiated (13.3\%) respectively (magnification $\times 400)$. P10, P7, P3 and P2 represent the derived sequences from the PCR products

56-65 years has the highest incidence $(26.7 \%)$ of cervical cancer cases reported in this study. This is in agreement with the previously documented peak age of incidence [26, 27].

There is a $92 \%$ chance of survival if cervical cancer is detected early but as documented by early researchers, most women still present late [3]. Although the Papanicolaou (Pap) smear test is an efficient screening tool that helps in early detection of cervical cancer or its predisposition, there was a poor cervical cancer screening (CCS) uptake by participants in this study. This is similar to the report by Ifemelumma et al. [3].

Most of the mutations detected in the samples in the present study are located within the central DNA binding domain (residues 102-292) of p53 and are particularly common in the four highly conserved domains in this region. This is consistent with previous reports [28, 29]. Silent mutations in the $p 53$ gene have been reported to be associated with poor prognosis of breast cancer [2] but a definitive link for cervical cancer is yet to be established. There is a possible synergism between silent mutations and missense mutations in cancer development [2, 14]. The effect of missense mutations in the $p 53$ gene brings about single amino acid substitutions, resulting in defective p53 conformation, leading to an inactive protein. Missense mutations are the most common mutations observed in our study, which is in line with report by Skaug et al. [30] of about $90 \%$ missense mutations in their study.

The codons Phe19, Trp23, and Leu26 are present on the transactivation domain of $p 53$, which makes them critical for MDM2 homologue binding, the principal $p 53$ cellular antagonist [31]. The present study revealed a frameshift mutation in codon 26 , which may lead to deregulation of MDM2, and its overexpression [32, 33] targeting p53 for rapid degradation [28]. An earlier report has suggested the primary involvement of point mutations in the $p 53$ gene, resulting in the substitution of amino acids in the protein's central region [34]. It was observed that the E6 oncoprotein inactivates the codon 72 arginine polymorph more easily compared to the proline polymorph, which has been associated with the outcome of HPV infections. Hence, women that have the arginine polymorph might be more susceptible to the effects of the oncogenic HPV types [8]. Ten (10) sequences, representing the four cancer differentiation stages were selected for analysis. Six sequences carry arginine polymorphism. This is corroborated by findings in a study on the Greek population [23]. There was a high presence of p53 arginine polymorphs in the tumour suppressor, which influences the susceptibility of an individual to cervical cancer [23]. Another finding [35] reported that the E6 oncoprotein from high-risk human papillomaviruses (HPVs) resulted in more efficient degradation of the arginine polymorph (R72) than the proline polymorph (P72). This drastically reduced cellular levels of p53 protein and increasing the risk of HPVassociated cancers in arginine homozygotes.

The T350G sequence variation leads to the amino acid substitution L83V in the E6 oncoprotein. Previous studies have suggested that the missense substitution of valine for leucine at codon 83 observed in our study (L83V) is attributed to viral persistence and thus it is regarded as a considerable risk factor for the development of severe dysplasia and cervical cancer [23]. In addition, tumour suppressor associated single nucleotide polymorphisms might directly or indirectly affect tumour progression as well as further 
interruption of cell cycles. Allelic polymorphisms that occur in the regulatory regions of these genes are closely associated with malignant cellular alterations [17]. Whereas tumour suppressors are commonly inactivated by frameshift (insertions or deletions) or nonsense mutations, most p53 mutations are missense and cause single amino-acid changes at many different positions [14].

Although several studies have reported the association of $\mathrm{p} 53$ protein accumulation and mutations with cancer prognosis [14, 17, 23], few have explored the $p 53$ gene mutational landscape with respect to the histopathological analyses in cervical cancer, especially in African populations. Most of the observed mutations in the present study were missense and silent mutations which suggest that the tumour suppressor gene, $p 53$, does not accumulate mutations so easily or spontaneously in cervical carcinogenesis (consistent with the findings of Tommasino et al. [28]). Therefore, mutation in this gene can be a very important biomarker to evaluate the development and extent of progression of cervical cancer [4]. An earlier report has suggested that advanced stage and cancer subtypes with aggressive behaviour have more frequent mutations leading to poor prognosis [14].

\section{Conclusions}

In this study, 19 mutational polymorphic variations in exons 3 and 4 of the $p 53$ gene were identified. Increased accumulation of mutational polymorphic variability in $p 53$ gene was found to be associated with increased severity of cervical cancer; especially in the sequence-specific DNAbinding domain. This tends to have a considerable impact on cervical cancer progression. The present study is limited by the sample size. Further study, using larger cohorts, will help to pinpoint specific polymorphic variability in $p 53$ gene with specific staging of cervical cancer. It may also be possible to investigate the clinical significance of the observed mutations on drug response amongst cervical cancer patients in the study population.

\section{Supplementary Information}

The online version contains supplementary material available at https://doi. org/10.1186/s43042-021-00144-1.

Additional file 1: Figure S1. Other ethidium bromide-stained agarose gel of the PCR products (350 bps) amplified from genomic DNA isolated from the cervical tissues using primers as specified in the methods section. The first lane $(\mathrm{L})$ represents the marker (50 base pair DNA ladder), lane (-ve) is the negative control (no DNA template), lane (+ve) is another control (template is genomic DNA from individual pre-tested to be cervical cancer free) and lanes S1-S12 are PCR products using genomic DNA templates from respective biopsy samples.

Additional file 2: Table S1. The nucleotide base sequence and parameters of the forward and reverse primers used for PCR amplification of the region of interest of p53 gene.

Additional file 3: Table S2. The composition of the polymerase chain reaction for gene amplification.

\section{Acknowledgements}

We acknowledge the medical staff members of the Obstetrics and Gynaecology Theatre, University College Hospital, Ibadan, for assistance with the collection of the samples, and those at the Professor Abideen Oluwasola Special Diagnostics Centre, University College Hospital, Ibadan, for sample storage and molecular biological preparations. We thank Dr. John Beeching (formerly of University of Bath, UK) who has kindly helped with English Language editing. This research study was partly supported by IBR-TETFUND grant 2016, University of Ibadan.

\section{Authors' contributions}

MAG designed the study, supervised the laboratory work, molecular and bioinformatics analyses and prepared the manuscript. OEO performed the experiments, acquired and analysed the data, molecular and bioinformatics analyses and prepared the draft manuscript. TAOO contributed to the study design, supervised the clinical samples collection, gynaecological analysis and prepared draft manuscript. CAO contributed to the study design and pathological analysis of the clinical samples. OS contributed to the study design and performed preliminary experiments. GOO contributed to the pathological analysis of the clinical samples, supervised molecular analysis. AOO contributed to the study design, pathological analysis and supervised molecular analysis. OAO contributed to the study design and supervised bioinformatics analysis. All authors contributed to the draft manuscript and approved the final version of the manuscript.

\section{Funding}

This research study was supported in part by IBR-TETFUND grant 2016, University of Ibadan, supplemented by personal funds.

\section{Availability of data and materials \\ Not applicable}

\section{Ethics approval and consent to participate}

The University College Hospital (UCH)-University of Ibadan Institution Ethics Committee approved the study, reference number UI/EC/17/0156. Written informed consents were obtained from all study participants before samples were taken.

\section{Consent for publication}

Publication was pre-approved subject to the confidentiality of the study participants.

\section{Competing interests}

Nil

\section{Author details}

${ }^{1}$ Cancer Research and Molecular Biology Laboratories, Department of Biochemistry, University of Ibadan, Ibadan, Nigeria. ${ }^{2}$ Department of Obstetrics and Gynaecology, College of Medicine, University of Ibadan, Ibadan, Nigeria. ${ }^{3}$ Department of Pathology, College of Medicine, University of Ibadan, Ibadan, Nigeria.

Received: 17 December 2020 Accepted: 9 February 2021

Published online: 01 April 2021

References

1. Shafi MI (2012) Premalignant and malignant disease of the cervix. In: Edmonds K (ed) Dewhurst's Textbook of Obstetrics \& Gynaecology. Eighth. John Wiley \& Sons, Ltd, Cambridge, pp 747-759

2. Odujoko OO, Komolafe AO, Adegoke A, Olasode BJ (2016) P53 and Ki67 expression by cervical cancers in lle-lfe, Nigeria. Br J Med Med Res 17(9):1-9. https://doi.org/10.9734/BJMMR/2016/21697

3. Ifemelumma CC, Anikwe CC, Okorochukwu BC et al (2019) Cervical cancer screening: assessment of perception and utilization of services among health workers in low resource setting. Int J Reprod Med 2019:1-8. https:// doi.org/10.1155/2019/6505482

4. Khan MA, Tiwari D, Dongre A, Sadaf MS, Das RC et al (2020) Exploring the p53 connection of cervical cancer pathogenesis involving northeast Indian patients. PLoS One 15(9):e0238500 https://doi.org/10.1371/ journal.pone.0238500 
5. Pinheiro NA, Villa LL (2001) Low frequency of p53 mutations in cervical carcinomas among Brazilian women. Braz J Med Biol Res 34:727-733

6. Garima PS, Pandey LK, Saxena AK, Patel N (2016) The role of p53 gene in cervical carcinogenesis. Obstet Gynecol India 66(1):383-388. https://doi. org/10.1007/s13224-015-0754-1

7. Scheffner M, Munger K, Byrne JC, Howley PM (1991) The state of the p53 and retinoblastoma genes in human cervical carcinoma cell lines. Proc Natl Acad Sci 88:5523-5527

8. Michelina S, Brenna F, Dale I et al (2004) Prevalence of codon 72 P53 polymorphism in Brazilian women with cervix cancer. Genet Mol Biol 27: 496-499

9. Ngan HYS, Stanley M, Liu S, Ma HK (1994) HPV and p53 in cervical cancer. Genitourin Med 70:167-170. https://doi.org/10.1136/sti.70.3.167

10. Shepherd T, Tolbert D, Benedetti J et al (2000) Alterations in exon 4 of the p53 gene in gastric carcinoma. Gastroenterology. 118:1039-1044. https:// doi.org/10.1053/gast.2000.7960

11. Gbadegesin MA, Soremekun O, Oluwasola TAO, Okolo CA, Oluwasola AO (2017) An overview of the genetics of cervical cancer. Arch Basic Appl Med 5(1):47-57

12. Makwane N, Saxena A (2009) Study of mutations in p53 tumour suppressor gene in human sporadic breast cancers. Indian J Clin Biochem 24(3):223-228

13. Zhao Y, Ren J, Wang M et al (2013) Codon 104 variation of p53 gene provides adaptive apoptotic responses to extreme environments in mammals of the Tibet plateau. PNAS. 110(51):20639-20644. https://doi.org/1 0.1073/pnas.1320369110

14. Olivier M, Hollstein M, Hainaut P (2010) TP53 mutations in human cancers: origins, consequences, and clinical use. Cold Spring Harb Perspect Biol:1-17. https://doi.org/10.1101/cshperspect.a001008

15. Freier CP, Stiasny A, Kuhn C et al (2016) Immunohistochemical evaluation of the role of p53 mutation in cervical cancer: Ser-20 p53 -mutant correlates with better prognosis. Anticancer Res 36:3131-3138

16. Levine AJ (1997) p53, the Cellular Gatekeeper for Growth and Division. Cell. 88:323-331

17. Hsieh Y, Lin C (2006) P53 codon 11, 72, and 248 gene polymorphisms in endometriosis. Int J Biol Sci 2(4):188-193

18. Robles Al, Harris CC (2010) Clinical outcomes and correlates of TP53 mutations and cancer. Cold Spring Harb Perspect Biol:1-16. https://doi.org/1 0.1101/cshperspect.a001016

19. Stiasny A, Freier CP, Kuhn C et al (2017) The involvement of E6, p53, p16, MDM2 and Gal -3 in the clinical outcome of patients with cervical cancer. Oncol Lett 14:4467-4476. https://doi.org/10.3892/ol.2017.6752

20. Koutb F, Abdel-rahman S, Hassona E, Haggag A (2017) Association of C-myc and p53 gene expression and polymorphisms with hepatitis $\mathrm{C}(\mathrm{HCV})$ chronic infection, cirrhosis and hepatocellular carcinoma (HCC) stages in Egypt. Asian Pac J Cancer Prev 18(8):2049-2057. https://doi.org/10.22034/A PJCP.2017.18.8.2049

21. Mcgregor JM, Harwood CA, Brooks L et al (2002) Relationship between p53 codon 72 polymorphism and susceptibility to sunburn and skin cancer. J Invest Dermatol 119(1):84-90. https://doi.org/10.1046/j.1523-174 7.2002.01655.x

22. Baker SJ, Fearon ER, Nigro JM et al (1989) Chromosome 17 deletions and p53 gene mutations in colorectal carcinomas. Science 244(4901):217-221. https://doi.org/10.1126/science.2649981

23. Moschonas GD, Tsakogiannis D, Lamprou KA et al (2017) Association of codon 72 polymorphism of p53 with the severity of cervical dysplasia, E6T350G and HPV16 variant lineages in HPV16-infected women cervical specimens. J Med Microbiol 66:1358-1365. https://doi.org/10.1099/jmm.0. 000563

24. Magali O, Thierry S, Jean-Christophe B, Nazneen $\mathrm{R}$ Homo sapiens tumor protein p53 (TP53), RefSeqGene (LRG_321) on chromosome 17. NCBI GenBank. https://www.ncbi.nlm.nih.gov/nuccore/NG_017013.2?from=5001 \&to=24149\&report=genbank. Published 2018

25. Parkin D, Whelan S, Ferlay J, Teppo L, Thomas D. Cancer incidence in five continents. 155th ed. (DM P, SL W, Al. E, eds.). IARC Scientific Publications; 2012.

26. Arulogun OS, Maxwell $O O$ (2012) Perception and utilization of cervica cancer screening services among female nurses in University College Hospital, Ibadan, Nigeria. Pan Afr Med J 11(69):1-8

27. Gibbs R, Beth K, Arthur H, Ingrid H (2008) Danforth's Obstetrics and Gynecology, 2008; 10th. In: Ronald G (ed) 10th. Lippincott Williams and Wilkins, Philadelphia, pp 971-988
28. Tommasino M, Accardi R, Caldeira S et al (2003) The role of TP53 in cervical carcinogenesis. Hum Mutat 21(3):307-312. https://doi.org/10.1002/humu.10178

29. Hollstein M, Sidransky D, Vogelstein B, Harris CC (1991) p53 mutations in human cancers. Science. 253(5015):49-53 http://www.ncbi.nlm.nih.gov/ pubmed/1905840.

30. Skaug V, Ryberg D, Kure EH et al (2000) p53 mutations in defined structural and functional domains are related to poor clinical outcome in non-small cell lung cancer patients 1. Clin Cancer Res 6(March):1031-1037

31. Teoh PJ, Chng WJ (2014) P53 abnormalities and potential therapeutic targeting in multiple myeloma. Biomed Res Int 2014:1-9. https://doi.org/1 $0.1155 / 2014 / 717919$

32. Wade M, Li YC, Wahl GM (2013) MDM2, MDMX and p53 in oncogenesis and cancer therapy. Nat Rev Cancer 13(2):83-96. https://doi.org/10.1038/nrc3430

33. Quesnel B, Preudhomme C, Oscier D et al (1994) Over-expression of the MDM2 gene is found in some cases of haematological malignancies. $\mathrm{Br} J$ Haematol 88(2):415-418. https://doi.org/10.1111/j.1365-2141.1994.tb05044.x

34. Lai H, Lin L, Nadji M et al (2002) Mutations in the p53 tumor suppressor gene and early onset breast cancer. Cancer Biol Ther 1(1):31-36. https://doi. org/10.4161/cbt.1.1.37

35. Whibley C, Pharoah PD, Hollstein M (2019) p53 polymorphisms: cancer implications. Medscape.:1-11 https://www.medscape.com/viewarticle/ 5877755 .

\section{Publisher's Note}

Springer Nature remains neutral with regard to jurisdictional claims in published maps and institutional affiliations.

\section{Submit your manuscript to a SpringerOpen ${ }^{\circ}$ journal and benefit from:}

- Convenient online submission

- Rigorous peer review

- Open access: articles freely available online

- High visibility within the field

- Retaining the copyright to your article

Submit your next manuscript at $>$ springeropen.com 